\title{
Evolutionary ecology of facultative paedomorphosis in newts and salamanders
}

\author{
Mathieu Denoël ${ }^{1,4}$, Pierre Joly ${ }^{2}$ and Howard H. Whiteman ${ }^{3,4}$ \\ ${ }^{1}$ Laboratory of Fish and Amphibian Ethology, Behavioural Biology Unit, Department of Environmental Sciences, University of Liège, \\ 22 Quai Van Beneden, 4020 Liège, Belgium (E-mail: Mathieu.Denoel@ulg.ac.be) \\ ${ }^{2}$ UMR CNRS 5023 Ecology of Fluvial Hydrosystems, Claude Bernard University of Lyon, 69622 Villeurbanne, France \\ ${ }^{3}$ Department of Biological Sciences, Murray State University, Murray, Kr 42071, USA \\ ${ }^{4}$ Rocky Mountain Biological Laboratory, P.O. Box 519, Crested Butte, CO 81224, USA
}

(Received 14 December 2004; revised 31 May 2005; accepted 8 June 2005)

\begin{abstract}
Facultative paedomorphosis is an environmentally induced polymorphism that results in the coexistence of mature, gilled, and fully aquatic paedomorphic adults and transformed, terrestrial, metamorphic adults in the same population. This polymorphism has been of interest to scientists for decades because it occurs in a large number of caudate amphibian taxa as well as in a large diversity of habitats. Numerous experimental and observational studies have been conducted to explain the proximate and ultimate factors affecting these heterochronic variants in natural populations. The production of each alternative phenotype is based on a genotype $\times$ environment interaction and research suggests that differences in the environment can produce paedomorphs through several ontogenetic pathways. No single advantage accounts for the maintenance of this polymorphism. Rather, the interplay of different costs and benefits explains the success of the polyphenism across variable environments. Facultative paedomorphosis allows individuals to cope with habitat variation, to take advantage of environmental heterogeneity in the presence of open niches, and to increase their fitness. This process is expected to constitute a first step towards speciation events, and is also an example of biodiversity at the intraspecific level. The facultative paedomorphosis system is thus ripe for future studies encompassing ecology, evolution, behaviour, endocrinology, physiology, and conservation biology. Few other systems have been broad enough to provide varied research opportunities on topics as diverse as phenotypic plasticity, speciation, mating behaviour, and hormonal regulation of morphology. Further research on facultative paedomorphosis will provide needed insight into these and other important questions facing biologists.
\end{abstract}

Key words: adaptation, amphibians, evolution, facultative paedomorphosis, heterochrony, polyphenism.

\section{GONTENTS}

I. Introduction

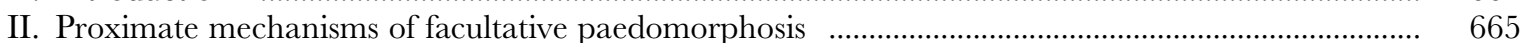

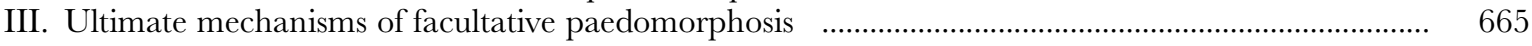

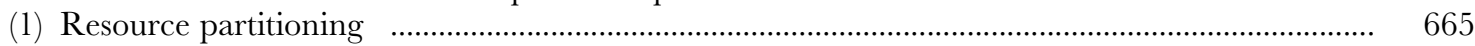

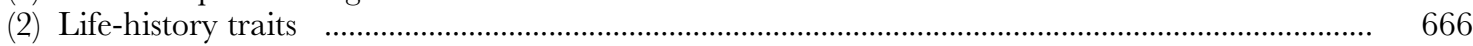

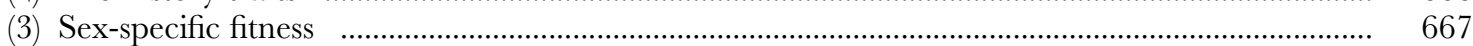

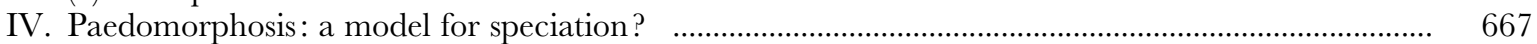

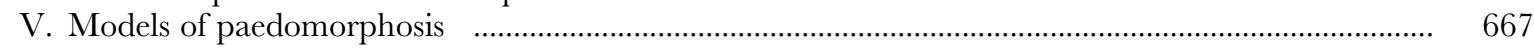

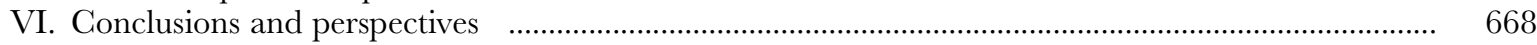

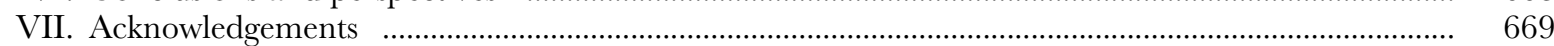

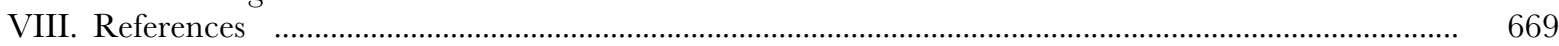




\section{INTRODUGTION}

Facultative paedomorphosis (i.e. the potential for retention of juvenile traits in mature individuals) has roused the curiosity of biologists for more than a century. This phenomenon was first suspected by Cuvier (1828) who was reluctant to place the axolotl in the permanently branchiate salamanders, but its existence was first demonstrated by Dumerill (1866) at the Museum of Paris when he bred branchiate individuals of Ambystoma mexicanum. The metamorphosis of these axolotls into a form that was known as another salamander species provided the first evidence of developmental heterochrony between the sexual apparatus and the somatic tissues. For decades, such heterochronies in the development of caudate amphibians remained a zoological curiosity until a satisfactory theoretical framework was established to explore some explanatory hypotheses. The first studies were mechanistic and did not address evolutionary questions (Snyder, 1956; Sprules, $1974 a$; Gabrion, 1976). They considered facultative paedomorphosis to be a metamorphic failure caused by the detrimental effects of varied environmental factors. The environmental context of paedomorphosis proved to be so diverse that it became evident that the determinism of this trait was multifactorial (Semlitsch, 1987 a; Breuil, 1992; Whiteman, 1994; Voss, 1995; Denoël, 2003a). Indeed, paedomorphosis occurs in such contrasting habitats as permanent mountain lakes surrounded by arid grounds and lowland temporary ponds surrounded by wet forests. The rise of modern evolutionary biology has opened new perspectives on this polymorphism, particularly within the framework of the evolution of phenotypic plasticity.

Phenotypic plasticity can result from heterochronic processes, consisting of a shift in the timing or rate of development of a functional set of biological traits relative to the development of the whole organism (Schlichting \& Pigliucci, 1998). In animals with complex life cycles, heterochronic processes are expected to have profound consequences because of the interplay between larval and postmetamorphic traits that can lead to substantial differences between alternative morphotypes. Subsequently, such polyphenism can have a strong impact on the evolution of ecological communities (Gould, 1977; McKinney \& McNamara, 1991).

Research suggests that genotypes able to produce alternative phenotypes would occur in heterogeneous environments in which each alternative can experience a higher fitness in the environment where the risks of suboptimal matching between resource availability and morpho-functional abilities are spread through phenotypic differentiation (Kaplan \& Cooper, 1984; Gross, 1991; Skulason \& Smith, 1995; Schlichting \& Pigliucci, 1998). However, the evolution of polyphenism implies that the fitness gain drawn from the ecological specialisation of different phenotypes exceeds the cost of plasticity. Thus, polyphenisms are expected in environments where the scale of variability matches the adaptive potential of the developing phenotype (Levins, 1968). With regard to life history, polyphenisms are particularly expected in species with complex life cycles because the transition between habitats via metamorphosis is risky due to the lack of reliable information about the quality of the subsequent habitat (Wilbur \& Collins, 1973; Werner, 1986). The ontogenetic pathway of species with complex life cycles is indeed characterized by the successive use of contrasting habitats (Nielsen, 1998). As a consequence, these species experience more environmental variation than single-habitat species. Selection for phenotypic plasticity is thus expected to be particularly strong in species with complex life cycles. The duration of each phase of a cycle should depend on the specific cost:benefit ratio (in terms of individual fitness) in each habitat.

Newts and salamanders exhibit a wide range of life cycles. At the extremes, some species can totally skip one stage and spend their whole life in only one habitat. This is the case in permanently gilled species (obligate paedomorphosis) that occupy aquatic habitats and of terrestrial species exhibiting direct development (Istock, 1967; Wilbur \& Collins, 1973; Wilbur, 1996). Between these extremes, many salamanders exhibit a two-stage ontogenetic pathway with a larval aquatic stage and a terrestrial post-metamorphic stage (obligate metamorphosis) (Wilbur, 1980), while others exhibit facultative paedomorphosis (Duellman \& Trueb, 1994). Each of these life cycles can be seen as a result of the interplay between costs and benefits experienced in both aquatic and terrestrial environments. Detrimental aquatic conditions (drying, crowding, low food availability, inbreeding, presence of predators) and unfavourable terrestrial situations (low humidity, absence of shelter, low food availability, high predation) may have driven species towards one of the basic life histories (Wilbur \& Collins, 1973; Whiteman, 1994).

Paedomorphosis has been observed in fifty-seven species of newts and salamanders, distributed in nine of the ten recognized families. Four of them are only composed of obligatory paedomorphic species (Amphiumidae, Sirenidae, Proteidae, Gryptobranchidae). Such obligate paedomorphosis also occurs in a few species of Plethodontidae. Paedomorphosis is facultative in the Salamandridae, Ambystomatidae, Dicamptodontidae, Hynobiidae and some Plethodontidae. More than $10 \%$ of salamander species exhibit paedomorphic ontogenetic pathways (Semlitsch \& Wilbur, 1989; Duellman \& Trueb, 1994; Whiteman, 1994; Denoël, $2003 a$ ).

Interest in facultative paedomorphosis grew in the 1980s (e.g. Semlitsch \& Gibbons, 1985; Harris, 1987; Semlitsch, $1987 a$; Semlitsch \& Wilbur, 1989) after Wilbur and Collins (1973) published their growth model of metamorphosis timing. Most advances until the early 1990s were summarised by Whiteman (1994) who proposed alternative models to account for the variation of ontogenetic pathways among facultative paedomorphic species in natural and experimental conditions. Numerous authors have subsequently used facultative paedomorphosis as a model system in which to investigate the genetic bases and benefits of polyphenism in natural populations (Voss, 1995; Kalezic et al., 1996; Whiteman, Wissinger \& Brown, 1996; Voss \& Shaffer, 1997; Whiteman, 1997; Ryan \& Semlitsch, 1998; Denoël \& Joly, 2000, 2001; Denoël, Poncin \& Ruwet, $2001 b$; Boorse \& Denver, 2002; Denoël et al., 2002). 


\section{PROXIMATE MEGHANISMS OF FACULTATIVE PAEDOMORPHOSIS}

Cross-breeding experiments of paedomorphic and metamorphic individuals produce Mendelian ratios, thus supporting a recessive gene coding for paedomorphosis (Tompkins, 1978). However, more recent intra- and interspecific crosses suggest a complex genetic basis (Harris et al., 1990; Voss \& Shaffer, 1997) that would differ among species (Shaffer \& Voss, 1996; Voss et al., 2003). Selection experiments (that remove metamorphic individuals at each generation) also support the hypothesis of high heritability of this trait, although the persistence of metamorphs in these experiments suggests an additive genetic basis (Semlitsch \& Wilbur, 1989).

A variety of environmental factors have been experimentally shown to affect the expression of facultative paedomorphosis. Variation in density of conspecifics (Harris, 1987; Semlitsch, 1987 a), desiccation rate (Semlitsch, $1987 a$; Semlitsch, Harris \& Wilbur, 1990), temperature (Svob, 1965; Sprules, 1974a), and food availability (Sprules, $1974 a$; Voss, 1995; Ryan \& Semlitsch, 2003) were shown to affect the proportions of larvae undertaking a paedomorphic pathway. Preliminary studies in amphibians suggest that stress hormones are the intermediate between environmental cues and metamorphosis (Denver, 1997; Boorse \& Denver, 2002). On the other hand, paedomorphs are able to metamorphose at the adult stage (one-way reversible plasticity), at least in some species. The rate of reversion can be affected by such factors as desiccation (Denoël, 2003c), starvation (Denoël \& Poncin, 2001) or thyroxine injection (Svob, 1965). However, the amount of time necessary to reach complete transformation of paedomorphic adults is often longer than that of larvae (Breuil, 1992; Denoël \& Poncin, 2001), possibly because of the antagonist effect of sex-steroid hormones on thyroxine secretion (Denver, Glennemeier \& Boorse, 2002). Experiments with standardized rearing conditions have shown that the sensitivity to environmental cues varies among populations (Semlitsch et al., 1990). Such interplay between environment and genotype may account for the variation of the metamorph:paedomorph ratio across populations and species (Denoël et al., 2001a).

\section{ULTIMATE MEGHANISMS OF FACULTATIVE PAEDOMORPHOSIS}

\section{(1) Resource partitioning}

The evolution of facultative paedomorphosis results in a risk-spreading strategy that promotes a diversity of habitat uses within a single progeny. Paedomorphosis thus increases the probability of differentiation among offspring in resource use. When a resource that is exploited by one phenotype is depleted, the offspring exhibiting the other phenotype can potentially exploit an alternative resource. Such resource partitioning may increase fitness when high density increases resource competition among offspring

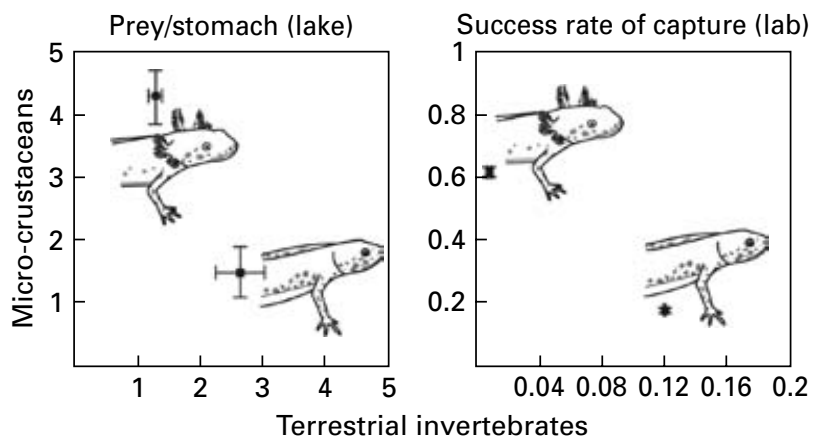

Fig. 1. Feeding habits (square-root transformed values) and performance of paedomorphic (drawn with gills) and metamorphic Alpine newts (modified from Denoël, 2004a; Denoël et al., 2004). The two alternative morphs segregate in resource use according to opposed performance in prey capture: higher predation and capture success for plankton in paedomorphs and on terrestrial invertebrates that fell on the water surface in metamorphs. Values are means $\pm \mathrm{SE}$ (feeding habits: $\mathrm{N}=174$ paedomorphs and 49 metamorphs; performance: $\mathrm{N}=20$ in each group).

(Skulason \& Smith, 1995; Smith \& Skulason, 1996; Denoël \& Joly, 2001).

Paedomorphosis in newts and salamanders involves the retention of the larval feeding apparatus. As a consequence, the hydrodynamics of paedomorph foraging relies on unidirectional water flow: water is drawn into the mouth by suction and is then expelled backwards through the gill slits. By contrast, the closed gill slits in metamorphs leads to water being expelled through the mouth, resulting in a forward backflow (Lauder \& Shaffer, 1993). The respective performance of each feeding morphology differs according to prey type. Whereas the unidirectional water flow system of the paedomorph oral apparatus is more efficient than the bidirectional flow of the metamorphs when foraging on aquatic prey (e.g., microcrustaceans) (Whiteman et al., 1996; Denoël, 2004a), it is less efficient when foraging on terrestrial insects that are caught at the water surface (Denoël, 2004a) (Fig. 1).

Resource use in deep lakes where the two morphs coexist is consistent with laboratory observations. In Alpine newts (Triturus alpestris), paedomorphs forage mainly on plankton while metamorphs search for terrestrial invertebrates at the water surface (Denoël \& Joly, 2001; Denoël \& Schabetsberger, 2003; Denoël, Schabetsberger \& Joly, 2004). In these populations, the two morphs either accrue similar caloric benefits or the paedomorphs have a higher food intake than the metamorphs, leading to better body condition (Denoël et al., 2002). In addition to food partitioning, the two morphs also segregate according to microhabitat in this species, because the paedomorphs are particularly frequent in both the water column and the deepest parts of the lake, while metamorphs mainly live in shallower water near the shore and at the water surface (Denoël \& Joly, 2001; Denoël \& Schabetsberger, 2003; also true of some ambystomatids: Whiteman \& Semlitsch, 2005). This habitat partitioning is congruent with breathing 
mechanisms, as only paedomorphs have gills, and with food partitioning, as planktonic organisms are abundant in open and deep waters while terrestrial invertebrates predominate at both shore and surface microhabitats. Risk spreading through facultative paedomorphosis (sensu Werner, 1986) thus appears to be a valuable mechanism for explaining the plasticity of the ontogenetic pathway (Fig. 1). However, microhabitat use and food partitioning are only local components of the life cycles of the newts. We also have to consider processes that constrain the evolution of polyphenism at larger habitat scales. For example, the usual absence of dispersal in paedomorphs is costly since they cannot leave a pond to reach more productive habitats, or to avoid competition, predation (including cannibalism) or inbreeding (Whiteman, 1994; Whiteman, Wissinger \& Bohonak, 1994; Whiteman et al., 1996; Denoël, 2004b). Dispersal can bring advantages in populations that inhabit pond archipelagoes where the costs of movements from one pond to another are low. Optimal change of habitat is not always directly related to the hydroperiod, but rather appears to be dependent on the quality and quantity of food resources as temporary ponds can be favourable foraging habitats (Whiteman et al., 1994; Whiteman et al., 1996; M. Denoël \& H. H. Whiteman, unpublished data).

Skulason \& Smith (1995) predicted that the absence of interspecific competition should favour trophic polymorphisms. Available data on heterochronic newts and salamanders support this hypothesis. In most places inhabited by paedomorphic newts, no vertebrate competitors (e.g. other species of urodeles or fishes) were found although resource use by predatory invertebrates and newts might be similar (Denoël et al., 2001a). When fishes are introduced, paedomorphs usually disappear rapidly from natural populations (Denoël, Dzukic \& Kalezic, 2005). This could be due to competition, or to predation since fish have a strong impact on paedomorphic newt populations because of their aquatic lifestyle and pelagic behaviour (Denoël \& Joly, 2001; Denoël \& Schabetsberger, 2003). However, larvae might also avoid the paedomorphic ontogenetic pathway in the presence of fish as has been suggested by mesocosm experiments (Jackson \& Semlitsch, 1993).

\section{(2) Life-history traits}

In newts and salamanders, paedomorphic phenotypes may be the product of different ontogenetic processes, the most frequent of them being progenesis and neoteny (Fig. 2). Progenesis consists of an acceleration of gonad development, which becomes functional at significantly younger ages than the usual onset of maturity in metamorphs. In contrast, neoteny results in slowing down the development of somatic structures, while the developmental rate of the gonads remains normal. Both processes lead to sexually mature individuals that retain larval somatic traits (Healy, 1974; Kalezic et al., 1996; Denoël \& Joly, 2000) (Fig. 2).

Similar to general predictions from models of heterochronic development (Gould, 1977; McKinney \& McNamara, 1991; Klingenberg, 1998), progenetic paedomorphs are usually smaller than metamorphic adults, as the former can reach sexual maturity several years before the

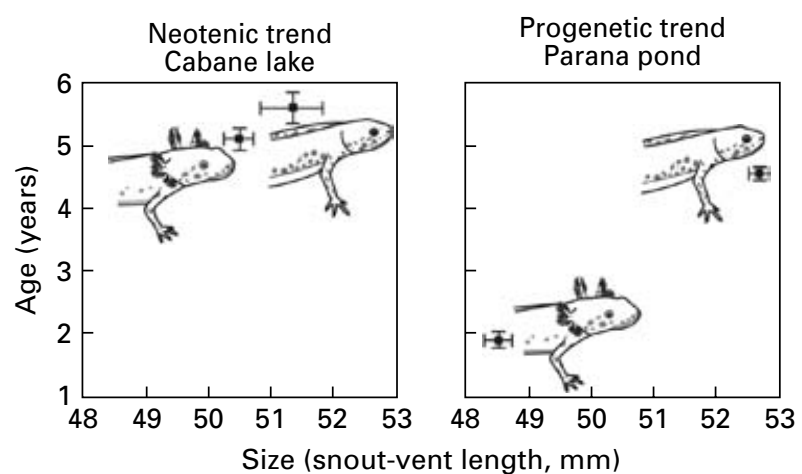

Fig. 2. Neotenic and progenetic processes in paedomorphosis (an example from Alpine newt populations). In progenesis, paedomorphs (drawn with gills) reach maturity at a younger age and smaller size than metamorphs. In neoteny, the pattern of sexual maturation and body growth remains unchanged in paedomorphs, but some parts of their soma develop slower than in metamorphs (modified from Denoël \& Joly, 2000). Values are means $\pm \mathrm{SE}$ (Cabane lake, age: $\mathrm{N}=62$ paedomorphs and 54 metamorphs, length: $\mathrm{N}=105$ and 47; Parana pond, age: $\mathrm{N}=57$ and 69, length: $\mathrm{N}=273$ and 400).

latter (Denoël \& Joly, 2000). However, when the two morphs differ in age at maturity by only a few weeks or months, they are more similar in size, indicating that skipping metamorphosis would likely provide more energy for somatic growth (Ryan \& Semlitsch, 1998). Age at maturity is thus probably an important target of natural selection for the evolution of facultative paedomorphosis (Ryan \& Semlitsch, 1998).

Fecundity is a critical fitness component for many organisms, including facultative paedomorphic salamanders (Semlitsch, 1985, 1987b). In some cases, paedomorphic females exhibit lower fecundity than their metamorphic counterparts (Semlitsch, 1985; Kalezic et al., 1996), but the reverse situation also exists (Semlitsch, 1985; Kalezic et al., 1996; Rot-Nikcevic, Kalezic \& Dzukic, 2000). Precocious oviposition by paedomorphic mole salamanders could result in their larvae gaining growth advantages over the larvae of metamorphs, which start breeding later in the season (Semlitsch, 1985). Early growth of the larvae may then translate into fitness benefits and higher survival later in life (Semlitsch, Scott \& Pechmann, 1988; Ryan \& Plague, 2004).

Maximization of individual reproductive success requires an optimal life cycle in terms of different traits, such as age at maturity and fecundity (Gross, 1985; Roff, 1992). Decreasing age at first reproduction or increasing the number of offspring at each breeding period will increase population growth rate, assuming no trade-offs with other life history traits (Roff, 1992). In newts and salamanders, paedomorphosis by progenesis has been observed in temporary ponds and neoteny in more permanent habitats (Healy, 1974; Denoël \& Joly, 2000). This is in agreement with models predicting risk-spreading by precocious maturity in unstable habitats (Gould, 1977; Roff, 1992). However, because clutch size is closely related to body size in amphibians (Semlitsch, 1985), reproducing at a small size probably 
reduces fecundity at first reproduction (Semlitsch, 1985). Nonetheless, because salamanders produce dozens to hundreds of eggs each year (Semlitsch, 1985; Kalezic et al., 1996), even a small decrease in the age at maturity can have fitness consequences that are similar to a large increase in fecundity (Roff, 1992). By maturing just one year after hatching and more than one year before metamorphic adults, progenetic paedomorphs also benefit from an increased probability of breeding that results in rapid increase in fitness (Denoël \& Joly, 2000).

\section{(3) Sex-specific fitness}

Sex-specific payoffs may influence the maintenance of polymorphism. By studying the time interval between breeding events in tiger salamanders, Whiteman (1997) showed that paedomorphic males bred more often than metamorphic males, while the reverse was true in females. This interaction effect promotes the maintenance of facultative paedomorphosis via sex-specific payoffs. The fact that paedomorphic females skip reproduction more often than metamorphic ones may be due to the low energy intake in permanent ponds and the high cost of egg production. The higher reproductive frequency in paedomorphic males is probably affected by their continued presence in breeding ponds, in contrast to metamorphic males, which depend on favourable climatic conditions (rainfall, temperature) during migration events from terrestrial overwintering sites. As predicted, the sex-ratio consistently differed between the two phenotypes with the males dominating in paedomorphs, and the females in metamorphs (Whiteman, 1997). The reverse of these sex ratios has been found in other populations, suggesting that the costs and benefits to each morph and sex vary by species and environmental conditions (Breuil, 1992; Whiteman, 1997; Ryan \& Hopkins, 2000; Denoël, $2003 a$ ).

\section{PAEDOMORPHOSIS : A MODEL FOR SPECIATION?}

Polymorphisms are suspected to be key steps in species evolution, particularly via sympatric differentiation where they promote reproductive isolation among morphs (Bush, 1994; Skulason \& Smith, 1995; West-Eberhard, 2003). In this way, assortative mating within alternative morphs could make offspring of paedomorphs less likely to metamorphose (Semlitsch \& Wilbur, 1989; Scott, 1993). Given differences in secondary sexual traits between morphs, sexual isolation might be expected. However, cross-breeding experiments in salamandrids showed that the two morphs interbreed successfully at an identical rate (Denoël et al., 2001b). Additional observations and experiments suggest that this also occurs frequently in ambystomatids (Krenz \& Sever, 1995; Whiteman, Gutrich \& Moorman, 1999). In several species, the two morphs display similar behavioural patterns at similar frequencies (Whiteman et al., 1999; Denoël et al., $2001 b$; Denoël, 2002) or exhibit only slight differences in the content and timing of courtship (Krenz \& Verrell, 2002).
They also use the same alternative tactics to attract females (Denoël, 2002, 2003b). This mating system differs from other polymorphisms in which morphs display alternative tactics or strategies with equal or different fitness payoffs (Gross, 1991, 1996; Fu, Neff \& Gross, 2001). Sexual compatibility promotes significant gene flow between morphs, and impedes differentiation as long as the environmental pressures do not change (Denoël et al., $2001 b$; Krenz \& Verrell, 2002). Thus even though facultative paedomorphosis is adaptive because of the flexibility it affords offspring, breeding studies suggest that this polymorphism is unlikely to lead to future speciation events.

Yet, in some salamander populations sexual isolation might occur because paedomorphs breed weeks or months earlier than metamorphs, thus leading to assortative mating (Whiteman \& Semlitsch, 2005). This situation might be reinforced by the low mating activity of females after first insemination (Krenz \& Sever, 1995). Spatial segregation of the two morphs in large ponds can also promote assortative mating among morphs (Whiteman \& Semlitsch, 2005). In these cases, temporal and spatial differences can lead to partial reproductive isolation, such that gene flow is reduced among certain morph-sex combinations (Whiteman \& Semlitsch, 2005).

Isolated permanent lakes or springs offer opportunities for divergence by allopatric speciation, particularly if the terrestrial morph is counter-selected. The spatial distribution of Mexican lakes where paedomorphic species of ambystomatid salamanders live provides such an ecological framework because they are isolated from each other by considerable amounts of inhospitable terrestrial habitat. As a consequence, paedomorphic populations of the different lakes evolve independently (Shaffer, 1993). A similar situation occurs in Eurycea salamanders (Plethodontids) which inhabit isolated springs on the Edwards Plateau in Texas (Chippindale et al., 2000). Obligatory paedomorphosis in some amphibian families might have arisen in such situations where life on land is counter-selected leading to a fully aquatic lifestyle. Even in less isolated systems, genetic differentiation of developmental mechanism was found in ambystomatid salamanders from South Carolina (Harris et al., 1990; Semlitsch et al., 1990). These results indicate that differentiation of developmental programs can occur quickly when gene flow among populations is low.

\section{MODELS OF PAEDOMORPHOSIS}

Both predictive and diversifying models of phenotypic plasticity have been proposed to account for the mechanisms leading to environmentally-induced phenotypes (Kaplan \& Cooper, 1984; Menu \& Debouzie, 1993). According to predictive plasticity models, phenotypes are induced following the perception of environmental indices that reliably inform the individual of future environmental conditions (Menu \& Debouzie, 1993). Paedomorphic responses to permanent water and low density support this model (Harris, 1987; Semlitsch, 1987 a). By undergoing metamorphosis following a decrease in water level and/or an increase 


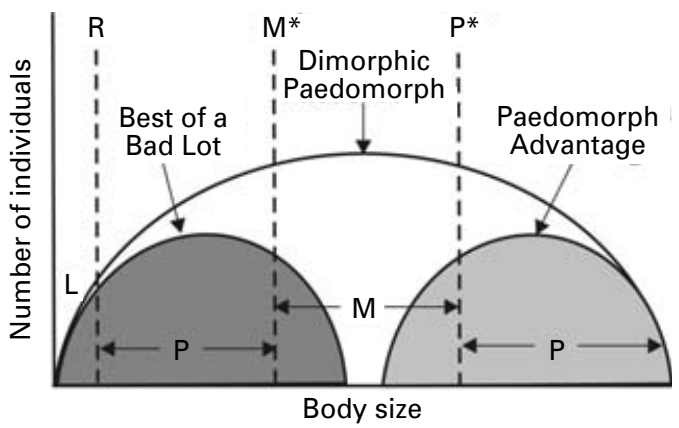

Fig. 3. Three ecological models of paedomorphosis (modified from Whiteman, 1994): the Best of a Bad Lot (dark shaded semi-circle), the Paedomorph Advantage (light shaded semicircle) and the Dimorphic Paedomorph Hypothesis (open semicircle). $R$ : minimum size for sexual maturity, $M^{*}$ : minimum size for metamorphosis, $P^{*}$ : minimum size for paedomorphosis through the Paedomorph Advantage model, $L$ : larval stage, $P$ : paedomorphic stage, $M$ : metamorphic stage.

in density, both larvae and, in some cases, paedomorphic adults escape an aquatic environment that is becoming unfavourable. Such a transition generally occurs just before the pond dries, allowing individuals to optimize the benefit of their aquatic habitat (Semlitsch et al., 1988; Denoël, 2003c). Food availability can also influence the ontogenetic pathway, but via a more complex mechanism. Whereas the frequency of metamorphosis increases in adult paedomorphs as aquatic food resources become scarce (thus supporting the predictive plasticity hypothesis) (Denoël \& Poncin, 2001), food limitation can delay metamorphosis in larvae (Sprules, $1974 a$; Voss, 1995; Ryan \& Semlitsch, 2003).

Whiteman (1994) modified the Wilbur-Collins metamorphosis model (Wilbur \& Collins, 1973) to create three hypotheses for the production and maintenance of facultative paedomorphosis according to habitat quality (Fig. 3). The Paedomorph Advantage (PA) mechanism corresponds to the basic model of Wilbur and Collins (1973). It predicts that large, fast-growing animals (larger than $\mathrm{P}^{*}$, the minimum size for paedomorphosis in Fig. 3) in good growing habitats (where growth rate is high) become paedomorphic, while animals smaller than $\mathrm{P}^{*}$ metamorphose to escape competition with larger paedomorphs. By contrast, the Best of a Bad Lot (BOBL) hypothesis predicts the reverse solution in poor habitats (low growth conditions): the larger larvae $\left(>\mathrm{M}^{*}\right.$, the minimum size for metamorphosis) metamorphose, while the smallest ones (between $\mathrm{R}$, the minimum size for sexual maturity, and $\mathrm{M}^{*}$ ) keep a larval somatic state and become reproductively mature. Finally, the Dimorphic Paedomorph (DP) hypothesis suggests that paedomorphosis results from both mechanisms according to the local conditions experienced by each individual.

These predictions assume that growth rate is a key integrative parameter, and that body size is related to fitness. For example, the PA hypothesis suggests that fast-growing larvae in rich habitats experience a fitness advantage in this habitat. By contrast, the BOBL hypothesis predicts that larvae that cannot reach a sufficient size for metamorphosis take advantage of early maturity as a stopgap solution.
Evidence for both hypotheses in the same population would support the DP.

Assuming a strong relationship between fitness parameters and body size (Semlitsch, 1985, 1987 a), the model predicts that paedomorphs produced through a PA mechanism would have higher fitness than metamorphs (e.g. in fecundity or mating success), while the reverse would be true when paedomorphs are produced through a BOBL mechanism (although there might be a decrease in age at first reproduction). The DP suggests that mean fitness might not differ between morphs within a population, but the variance in fitness should be greater in paedomorphs than metamorphs because paedomorphs are produced through two mechanisms that differ strongly in their fitness payoffs.

Although a number of studies have supported both the PA and BOBL hypotheses (Whiteman, 1994; Whiteman et al., 1996; Denoël \& Joly, 2000; Ryan \& Semlisch, 2003; J. M. Doyle \& H. H. Whiteman, unpublished data), by far the most support has been found for PA, perhaps due in part to the good growing conditions in which many studies have been conducted. It is clear from experimental and observational studies of larval growth patterns that both mechanisms can operate to produce paedomorphs in nature; what is less clear is how the fitness consequences of each morph correspond to the hypotheses, if they do so at all. Because current studies have only addressed fitness components and not lifetime reproductive success (LRS), our ability to evaluate this question may have to wait until more complete LRS analyses of facultatively paedomorphic species are performed.

\section{CONGLUSIONS AND PERSPEGTIVES}

(1) Facultative paedomorphosis occurs in habitats as diverse as deep oligotrophic permanent alpine lakes and small eutrophic temporary ponds, surrounded by arid areas as well as by wet forests (Healy, 1974; Sprules, 1974b; Breuil, 1992; Whiteman, 1994; Denoël et al., 2001 a). The diversity of these environments, and the animals within them, has made it challenging to create a satisfactory explanatory framework. By identifying the multiple pathways that can drive an individual toward paedomorphosis, recent studies now make it possible to draw a conceptual framework for explaining the evolutionary success of facultative paedomorphosis in a great diversity of environments (Semlitsch, 1987 b; Whiteman et al., 1996; Voss \& Shaffer, 1997; Whiteman, 1997 ; Ryan \& Semlitsch, 1998; Denoël \& Joly, 2000, 2001; Denoël et al., 2002).

(2) Although many studies have been conducted to explain the existence and maintenance of polymorphisms, and particularly facultative paedomorphosis, the mechanism(s) of its expression remains poorly understood (Denver et al., 2002; Voss et al., 2003).

(3) New methods, such as candidate gene analysis, that have recently been used to determine the alleles involved in the timing of metamorphosis will increase our knowledge in the area (Voss et al., 2003).

(4) New research should also focus on the molecular transcription of signals that induce larvae to become 
paedomorphs and not metamorphs. Stress hormones are obvious key targets for the mediation between environmental cues and resulting developmental pathways (Boorse \& Denver, 2002), yet little work has focused on the hormonal basis of paedomorphosis.

(5) Recent work suggests that sex should also be incorporated into models to explain the maintenance of polymorphism (Whiteman, 1997). Further studies, in particular those dealing with hormones, should take sex effects into account as sex hormones act on the processes of metamorphosis (Denver et al., 2002).

(6) Finally, fluctuations in natural populations of paedomorphic newts and salamanders need to be explained in regard to natural and anthropogenic causes, including how the polymorphism might affect the frequency, amplitude, and metapopulation effects of fluctuation (Denoël et al., 2005; Whiteman \& Wissinger, 2005). Rapid environmental changes in systems composed of permanent and drying ponds are of particular interest (Healy, 1974; Kalezic \& Dzukic, 1985; Breuil, 1992; Whiteman et al., 1996).

(7) The facultative paedomorphosis system is thus ripe for future studies encompassing ecology, evolution, behaviour, endocrinology, physiology, and conservation biology. Few other systems have been broad enough to provide varied research opportunities on topics as diverse as phenotypic plasticity, speciation, mating behaviour, and hormonal regulation of morphology. Further research on facultative paedomorphosis is sure to provide needed insight into these and other important questions facing biologists.

\section{AGKNOWLEDGEMENTS}

We are grateful to N. Gerlanc, B. Kobylarz, J. Boynton, J. Doyle, and C. Eden for their useful comments on the manuscript. M. Denoël is a Research Associate at the FNRS (Belgian National Fundation for Scientific Research) and benefited from a Fulbright grant and FNRS grants 'credit aux chercheurs' 1.5.011.03 and 1.5.120.04, and Crédits pour brefs séjours. H. Whiteman was supported by NSF grant DEB-0109436, a Senior Research Fellowship from the Center for Field Biology, Austin Peay University, and by grants from the Center for Institutional Studies and Research at Murray State University.

\section{REFERENGES}

Boorse, G. G. \& Denver, R. J. (2002). Acceleration of Ambystoma tigrinum metamorphosis by corticotropin-releasing hormone. Journal of Experimental Zoology 293, 94-98.

Breuil, M. (1992). La néoténie dans le genre Triturus: mythes et réalités. Bulletin de la Société Herpétologique de France 61, 11-44.

Bush, G. L. (1994). Sympatric speciation in animals: new wine in old bottles. Trends in Ecology and Evolution 9, 285-288.

Ghippindale, P. T., Price, A. H., Wiens, J.J. \& Hillis, D. M. (2000). Phylogenetic relationships and systematic revision of central texas hemidactyliine plethodontid salamanders. Herpetological monographs 14, 1-80.

Guvier, G. (1828). Le Règne animal distribué d'après son Organisation. Chez Déterville, Paris.
DenoëL, M. (2002). Paedomorphosis in the Alpine newt (Triturus alpestris): decoupling behavioural and morphological change. Behavioral Ecology and Sociobiology 52, 394-399.

DenoëL, M. (2003a). Avantages sélectifs d'un phénotype hétérochronique. Eco-éthologie des populations pédomorphiques du Triton alpestre, Triturus alpestris (Amphibia, Caudata). Cahiers d'Ethologie 21, 1-327.

DenoëL, M. (2003b). Effect of rival males on the courtship of paedomorphic and metamorphic Triturus alpestris. Copeia 2003, 618-623.

DenoëL, M. (2003c). How do paedomorphic newts cope with lake drying? Ecography 26, 405-410.

DenoëL, M. (2004a). Feeding performance in heterochronic Alpine newts is consistent with trophic habits and maintenance of polymorphism. Ethology 110, 127-136.

DenoËL, M. (2004b). Terrestrial versus aquatic foraging in juvenile Alpine newts (Triturus alpestris). Ecoscience 11, 404- 409.

Denoël, M., Duguet, R., Dzukic, G., Kalezic, M. \& Mazzotti, S. (2001a). Biogeography and ecology of paedomorphosis in Triturus alpestris (Amphibia, Caudata). Fournal of Biogeography 28, 1271-1280.

Denoël, M., Dzukic, G. \& Kalezic, M. (2005). Effect of widespread fish introductions on paedomorphic newts in Europe. Conservation Biology 19, 162-170.

Denoët, M., Hervant, F., Schabetsberger, R. \& Joly, P. (2002). Short- and long term advantages of an alternative ontogenetic pathway. Biological Fournal of the Linnean Society 77, 105-112.

DenoëL, M. \& Joly, P. (2000). Neoteny and progenesis as two heterochronic processes involved in paedomorphosis in Triturus alpestris (Amphibia: Caudata). Proceedings of the Royal Society of London, Biological Sciences 267, 1481-1485.

DenoëL, M. \& Joly, P. (2001). Adaptive significance of facultative paedomorphosis in Triturus alpestris (Amphibia, Caudata): resource partitioning in an alpine lake. Freshwater Biology 46, $1387-1396$.

DenoëL, M. \& Poncin, P. (2001). The effect of food on growth and metamorphosis of paedomorphs in Triturus alpestris apuanus. Archiv fü Hydrobiologie 152, 661-670.

DenoëL, M., Poncin, P. \& Ruwet, J. C. (2001b). Sexual compatibility between two heterochronic morphs in the Alpine newt, Triturus alpestris. Animal Behaviour 62, 559-566.

Denoël, M. \& Schabetsberger, R. (2003). Resource partitioning in two heterochronic populations of Greek Alpine newts, Triturus alpestris veluchiensis. Acta Oecologica 24, 55-64.

Denoël, M., Schabetsberger, R. \& Joly, P. (2004). Trophic specializations in alternative heterochronic morphs. Naturwissenschaften 91, 81-84.

Denver, R.J. (1997). Environmental stress as a developmental cue: corticotropin-releasing hormone is a proximate mediator of adaptive phenotypic plasticity in amphibian metamorphosis. Hormones and Behavior 31, 169-179.

Denver, R.J., Glennemeier, K. S. \& Boorse, G. C. (2002). Endocrinology of complex life cycles: amphibians. In Hormones, Brain and Behaviour, Vol. 2 (eds. D. Pfaff, A. Arnold, A. Etgen, S. Fahrbach and R. Rubin), pp. 469-513. Academic Press.

Duellman, W. E. \& Trueb, L. (1994). Biology of Amphibians. The John Hopkins University Press, Baltimore, Maryland.

Dumerill, A. (1866). Observations faites à la ménagerie du muséum d'histoire naturelle sur la reproduction des axolotls batraciens urodèles à branchies extérieures et sur les métamorphoses qu'ils y ont subies. Bulletin de la Société Impériale d'Acclimatation, 1-11. 
Fu, P., Neff, B. D. \& Gross, M. R. (2001). Tactic-specific success in sperm condition. Proceedings of the Royal Society of London, Biological Sciences, Series B 268, 1105-1112.

Gabrion, J. (1976). La néoténie chez Triturus helveticus Raz. Etude morphofonctionnelle de la fonction thyroidienne. $\mathrm{PhD}$ Thesis, Université des Sciences et Techniques du Languedoc, Montpellier.

Gould, S.J. (1977). Ontogeny and Phylogeny. Harvard University Press, Harvard.

Gross, M. R. (1985). Disruptive selection for alternative life histories in salmon. Nature 313, 47-48.

Gross, M. R. (1991). Salmon breeding behavior and life history evolution in changing environments. Ecology 72, 1180-1186.

Gross, M. R. (1996). Alternative reproductive strategies and tactics: diversity within sexes. Trends in Ecology and Evolution 11, 92-98.

HARris, R. N. (1987). Density-dependent paedomorphosis in the salamander Notophthalmus viridescens dorsalis. Ecology 68, 705-712.

Harris, R. N., Semlitsch, R. D., Wilbur, H. M. \& Fauth, J. E. (1990). Local variation in the genetic basis of paedomorphosis in the salamander Ambystoma talpoideum. Evolution 44, $1588-1603$

Healy, W. R. (1974). Population consequences of alternative life histories in Notophthalmus v. viridescens. Copeia 1974, 221-229.

Istock, C. A. (1967). The evolution of complex life cycle phenomena: an ecological perspective. Evolution 21, 592-605.

Jackson, M. E. \& Semlitsch, R. D. (1993). Paedomorphosis in the salamander Ambystoma talpoideum: effects of a fish predator. Ecology 74, 342-350.

Kalezic, M. L., Gvetkovic, D., Djorovic, A. \& Dzukic, G. (1996). Alternative life-history pathways: paedomorphosis and adult fitness in European newts (Triturus vulgaris and T. alpestris). Fournal of Zoological Systematics and Evolutionary Research $34,1-7$.

Kalezic, M. L. \& Dzukic, G. (1985). Ecological aspects of the smooth newt (Triturus vulgaris) paedomorphosis from Montenegro. Arhiv Bioloskih Nauka 37, 43-50.

Kaplan, R. H. \& CoOper, W. S. (1984). The evolution of developmental plasticity in reproductive characteristics: an application of the 'adaptive coin-flipping' principle. The American Naturalist 123, 393-410.

KuingenberG, C. P. (1998). Heterochrony and allometry: the analysis of evolutionary change in ontogeny. Biological Reviews of the Cambridge Philosophical Society 73, 79-123.

Krenz, J. D. \& Sever, D. M. (1995). Mating and oviposition in paedomorphic Ambystoma talpoideum precedes the arrival of terrestrial males. Herpetologica 51, 387-393.

Krenz, J. D. \& Verrell, P. A. (2002). Integrity in the midst of sympatry: does sexual incompatibility facilitate the coexistence of metamorphic and paedomorphic mole salamanders (Ambystoma talpoideum)? Fournal of Zoology 258, 435-440.

Lauder, G. V. \& Shaffer, H. B. (1993). Design of feeding systems in aquatic vertebrates: major patterns and their evolutionary interpretations. In The Skull, Vol. 3: Functional and Evolutionary Mechanisms (eds. J. Hanken and B. K. Hall), pp. 113-149. Chicago University Press, Chicago.

Levins, R. (1968). Evolution in Changing Environments. Some Theoretical Explorations. Princeton University Press, Princeton.

MaKinney, M. L. \& MaNamara, K. J. (1991). Heterochrony. The Evolution of Ontogeny. Plenum Press, New York.

Menu, F. \& Debouzie, D. (1993). Coin-flipping plasticity and prolonged diapause in insects: example of the chestnut weevil
Curculio elephas (Coleoptera: Curculionidae). Oecologia 93, 367-373.

Nielsen, G. (1998). Origin and evolution of animal life cycles. Biological Reviews of the Cambridge Philosophical Society 73, 125-155.

Roff, D. A. (1992). The evolution of life histories. Theory and analysis. Chapman \& Hall, New York.

Rot-Nikcevic, I., Kalezic, M. L. \& Dzukic, G. (2000). Paedogenesis, life history traits and sexual dimorphism: a case study of the smooth newt, Triturus vulgaris, from Pannonia. Folia Zoologica 49, 41-52.

Ryan, T. J. \& Hopkins, W. A. (2000). Interaction of sex and size and the standard metabolic rate of paedomorphic Ambystoma talpoideum: size does matter. Copeia 2000, 808-812.

Ryan, T.J. \& Plague, G. R. (2004). Hatching asynchrony, survival, and the fitness of alternative adult morphs in Ambystoma talpoideum. Oecologia 140, 46-51.

Ryan, T.J. \& Semlitsch, R. D. (1998). Intraspecific heterochrony and life history evolution: decoupling somatic and sexual development in a facultatively paedomorphic salamander. Proceedings of the National Academy of Sciences of the United States of America 95, $5643-5648$

Ryan, T. J. \& Semlitsch, R. D. (2003). Growth and the expression of alternative life cycles in the salamander Ambystoma talpoideum (Caudata: Ambystomatidae). Biological Journal of the Linnean Society 80, 639-646.

Schlichting, C. D. \& Pigliucci, M. (1998). Phenotypic Evolution. A Reaction Norm Perspective. Sinauer, Sunderland.

ScotT, D. E. (1993). Timing of reproduction of paedomorphic and metamorphic Ambystoma talpoideum. The American Midland Naturalist 129, 397-402.

Semlitsch, R. D. (1985). Reproductive strategy of a facultatively paedomorphic salamander Ambystoma talpoideum. Oecologia, Berlin 65, 305-313.

Semlitsch, R. D. (1987a). Paedomorphosis in Ambystoma talpoideum: effects of density, food, and pond drying. Ecology 68, 994-1002.

Semlitsch, R. D. (1987b). Density-dependent growth and fecundity in the paedomorphic salamander Ambystoma talpoideum. Ecology 68, 1003-1008.

Semlitsch, R. D. \& Gibbons, J. W. (1985). Phenotypic variation in metamorphosis and paedomorphosis in the salamander Ambystoma talpoideum. Ecology 66, 1123-1130.

Semlitsch, R. D., Harris, R. N. \& Wilbur, H. M. (1990). Paedomorphosis in Ambystoma talpoideum: maintenance of population variation and alternative life-history pathways. Evolution 44, 1604-1613.

Semlitsch, R. D., Scott, D. E. \& Pechmann, J. H. K. (1988). Time and size at metamorphosis related to adult fitness in Ambystoma talpoideum. Ecology 69, 184-192.

Semlitsch, R. D. \& Wilbur, H. M. (1989). Artificial selection for paedomorphosis in the salamander Ambystoma talpoideum. Evolution 43, 105-112.

Shaffer, H. B. (1993). Phylogenetics of model organisms: the laboratory axolotl, Ambystoma mexicanum. Systematic Biology 42, 508-522.

Shaffer, H. B. \& Voss, S. R. (1996). Phylogenetic and mechanistic analysis of a developmentally integrated character complex: alternate life history modes in ambystomatid salamanders. The American Zoologist 36, 24-35.

Skulason, S. \& Smith, T. B. (1995). Resource polymorphisms in vertebrates. Trends in Ecology and Evolution 10, 366-370. 
Smith, T. B. \& Skulason, S. (1996). Evolutionary significance of resource polymorphisms in fishes, amphibians, and birds. Annual Review of Ecology and Systematics 27, 111-133.

SNyder, R. C. (1956). Comparative features of the life histories of Ambystoma gracile (Baird) populations at low and high altitudes. Copeia 1956, 41-50.

Sprules, W. G. (1974a). Environmental factors and the incidence of neoteny in Ambystoma gracile (Baird) (Amphibia: Caudata). Canadian Fournal of Zoology 52, 1545-1552.

SPRules, W. G. $(1974 b)$. The adaptive significance of paedogenesis in North American species of Ambystoma (Amphibia: Caudata): an hypothesis. Canadian Fournal of Zoology 52, 393-400.

Svob, M. (1965). Neurosekretion in Triturus alpestris montenegrinus Radov. und ihre korrelation mit der neotenie. Bulletin Scientifique, Beograd, A 10, 379-381.

Tompkins, R. (1978). Genic control of axolotl metamorphosis. The American Zoologist 18, 313-319.

Voss, S. R. (1995). Genetic basis of paedomorphosis in the axolotl, Ambystoma mexicanum: a test of the single-gene hypothesis. Fournal of Heredity 86, 441-447.

Voss, S. R., Prudic, K. L., Oliver, J. C. \& Shaffer, H. B. (2003). Candidate gene analysis of metamorphic timing in ambystomatid salamanders. Molecular Ecology 12, 1217-1223.

Voss, S. R. \& Shaffer, H. B. (1997). Adaptive evolution via a major gene effect: Paedomorphosis in the Mexican axolotl. Proceedings of the National Academy of Sciences of the United States of America 94, 14185-14189.

Werner, E. E. (1986). Amphibian metamorphosis: growth rate, predation risk, and the optimal size at transformation. The American Naturalist 128, 319-341.

West-Eberhard, M.J. (2003). Developmental Plasticity and Evolution. Oxford University Press.
Whiteman, H. H. (1994). Evolution of facultative paedomorphosis in salamanders. Quarterly Review of Biology 69, 205-221.

Whiteman, H. H. (1997). Maintenance of polymorphism promoted by sex-specific fitness payoffs. Evolution 51, 2039-2044.

Whiteman, H. H., Gutrich, J.J. \& Moorman, R. S. (1999). Courtship behavior in a polymorphic population of the tiger salamander, Ambystoma tigrinum nebulosum. Fournal of Herpetology 33, 348-351.

Whiteman, H. H. \& Semlitsch, R. D. (2005). Evidence for partial reproductive isolation among polymorphic salamanders. Biological Fournal of the Linnean Society, in press.

Whiteman, H. H. \& Wissinger, S. A. (2005). Amphibian population cycles and long-term data sets. In Amphibian declines. Status and Conservation of U.S. Amphibians (ed. M. L. Lannoo), pp. 177-184. California University Press.

Whiteman, H. H., Wissinger, S. A. \& Bohonak, A. J. (1994). Seasonal movement patterns in a sub-alpine population of the tiger salamander, Ambystoma tigrinum nebulosum. Canadian Fournal of Zoology 72, 1780-1787.

Whiteman, H. H., Wissinger, S. A. \& Brown, W. S. (1996). Growth and foraging consequences of facultative paedomorphosis in the tiger salamander, Ambystoma tigrinum nebulosum. Evolutionary Ecology 10, 433-446.

Wilbur, H. M. (1980). Complex life cycles. Annual Review of Ecology and Systematics 11, 67-93.

Wilbur, H. M. (1996). Multistage life cycles. In Population Dynamics in Ecological Space and Time (eds. O. E. Rhodes, R. K. Chesser and M. H. Smith), pp. 75-107. University of Chicago Press, Chicago.

Wilbur, H. M. \& Collins, J. P. (1973). Ecological aspects of amphibian metamorphosis. Science 182, 1305-1314. 